\title{
FINTECH, BIGTECH AND DIGITIZATION IMPACT EVALUATION IN BUSINESS MODELS OF THE BANKS
}

\author{
Oona VOICAN \\ The Bucharest University of Economic Studies \\ oona.voican@yahoo.com
}

\begin{abstract}
The explosive development of artificial intelligence, machine learning and big data methods in the last 10 years has been felt in the financial-banking, field which has subjected to profound changes aimed at determining an unprecedented increase in the efficiency and profitability of the businesses they carry out. The tendencies of applying the concepts coming from AI, together with the continuous increase of the volume, complexity and variety of the data that the banks collect, store and process have acquired the generic names of FinTech, respectively BigTech. Five main areas exist where FinTech and BigTech can provide improvements in business models for the banks: introducing specialized platforms, covering neglected customer segments, improving customer selection, reduction of the operating costs of the banks, and optimization of the business processes of the banks. This paper present some of these improvements, and show how the business models of the banks dramatically transform under the influence of these changes.
\end{abstract}

Keywords: Artificial intelligence, BigTech, Business models, Digitization impact evaluation, FinTech.

JEL classification: C6, G21.

DOI: $10.24818 / \mathrm{ie} 2020.04 .04$

\section{Introduction}

The development of the digital economy in the last period affects all sectors of activity, including the banks and financial sector. Within it, banks have a special role, as engines of economic growth in all sectors of the economy.

A new way of thinking is imposed on the banks through the transition to the digital economy. On the one hand, the financial sector and banks are causing huge changes in the way companies and other economic organizations operate and, on the other hand, this sector is undergoing dramatic changes that make the traditional concepts of banks themselves need redefining. This interdependence between the changes to which the two basic components are subject, the companies, on the one hand, and the financial-banking sector, on the other, is best illustrated by the evolution of the business models of the banks. Consequently, the financial system includes a new component - FinTech. This fundamentally changes the financial market, and technological innovation blurs the boundaries between financial products and services and subjects either authorized to offer its or actually involved in providing them (EBA, 2017).

The main purpose of this paper is to analyze the strategies adopted by the different types of new entrants to the financial market (FinTech, BigTech and the usual financial firms) in the provision of banking services and to examine how digitization affects the business models of banks and other providers of banking services.

FinTech. Most commonly used today in the literature is the working definition of the Financial Stability Board (FSB) for FinTech as a "technologically activated financial innovation, which could result in new business models, applications, processes or products with an associated 
material effect on financial markets and institutions and in the provision of financial services." (FSB, 2019). The focus of this definition is on analyzing the implications on the effects of FinTech in banks and other financial-banking institutions.

A first observation made in the literature regarding the meaning of the various definitions of FinTech, as they are now understood, shows that it is perceived in relation to an innovative service, a new business model (which can be used by a regular bank or by a certain company) or a new software program used within a start-up that determines a strong imitative current in the financial industry. A second observation is that some definitions distinguish between innovation and disruption, the first leading to the improvement of pre-existing rules in an existing regulatory framework, while the second leading to the emergence and rapid development of new rules that subsequently determine dramatically changing the framework of existing regulations.

BigTech is a generic name that is used for large technology companies active worldwide, having a relative advantage in using digital technology. BigTech companies are usually providers of web services (search engines (SEO), social networks, e-commerce etc.) for endusers on the internet and/or IT platforms or develop and maintain an infrastructure (storage and processing capabilities data) for which other regular companies provide products or services. Like FinTech companies, BigTech companies are usually automated and use agile processes for software developments, giving them multiple possibilities to quickly adapt their systems and services to the needs and wants of users. Relevant examples of BigTech companies are Google, Amazon, Facebook and Apple, known as the GAFA group.

\section{Literature review}

Business models are, in the last two decades, a highly popular subject of analysis, especially because they can best explain the differences that are observed between the results of different firms (Afuah and Tucci, 2003).

Initially, the notion of business model was mainly used in the field of management studies (Zott and Amit, 2011). During that period, a business model was understood as a business strategy, which was based on the balance sheet ratios and income accounts associated with them. The own studies on banking business models appear for the first time in the early works of (Amel and Rhoades, 1999) and Mehra (1996).

The structural business model is placed between the strategic and operational level in the architecture of the companies (Osterwalder, 2004). While the strategic level determines the milestones and the long-term source of a competitive advantage, the operational level shows what needs to be done to achieve the long-term objectives. (Casadesus-Masanell and Ricart, 2010). Studies on business models frequently use numerous well-established research branches, such as strategic management, information systems and management of innovation and change at firm level (Zott and al., 2011). However, many of the definitions address business models not only as a lot of specific elements, but also from the perspective of how they are interconnected and mutually influenced (Casadesus-Masanell and Zhu, 2013).

Baden-Fuller and Morgan (2010) identify three major reasons for building a business model: a method of classifying existing business types, a way of analysis for academic studies and a recipe for practitioners who want to reproduce and innovate successful models. However, as shown in recent literature, the approaches so far do not converge towards a common theoretical framework (Zott et al., 2011), nor can we find a dominant approach (Casadesus-Masanell and Zhu, 2013).

Regarding the business models of banks, many papers in recent years have proposed a classification of them into three broad categories, namely: significant, intuitive and based on 
quantitative characteristics of classified banks. These approaches can be classified based on the methodologies used as follows:

1) Studies that use clustering to classify banks based on a set of characteristics. The clustering methodology used uses an algorithm that assigns elements (in this case banks) to the clusters so as to minimize the distance between the elements of a single cluster and to maximize the distance between the average/median/centroid of the formed clusters. These works are mostly based on the agglomerative clustering hierarchy method described by Ward (1963) or the partial clustering method based on the algorithm of Vichi and Kiers (2001).

2) Studies that use qualitative approaches to classify banks according to the business model. These studies introduce a predefined classification of the business model, based on the activities, financing and legal structure of the banks. Banks are then assigned to each of these categories based on expert judgment. Starting with the first group of papers using the clustering methodology, Ayadi et al. (2011) explore which variables are relevant for defining a banking business model and provide preliminary evidence on the importance of business model analysis in banking regulation and supervision.

In (Ayadi et al., 2016), the authors obtained five types of banks based on a cluster hierarchy algorithm. Examples of such business models are Canvas by Osterwalder and Pigneur (2010), Wirtz's business model, Siemens Business Model Framework BizMo (Mütze and Gerloff, 2019) or the St Galen Management Model (SGMM). One of the best-known business models is Canvas, developed by A. Osterwalder (2004), which offers a visual representation of the business models used by strategic management.

In recent years, however, the Canvas model has been replaced by other more evolved models, for example with the iOcTen business model (Doleski, 2015), which, unlike the previous model, has the advantage that it allows the integration of the ten defined characteristics, taking into account permanently the changes and transformations that take place both inside and in the environment of the company.

"Figure 1" shows the basic components of this business model.

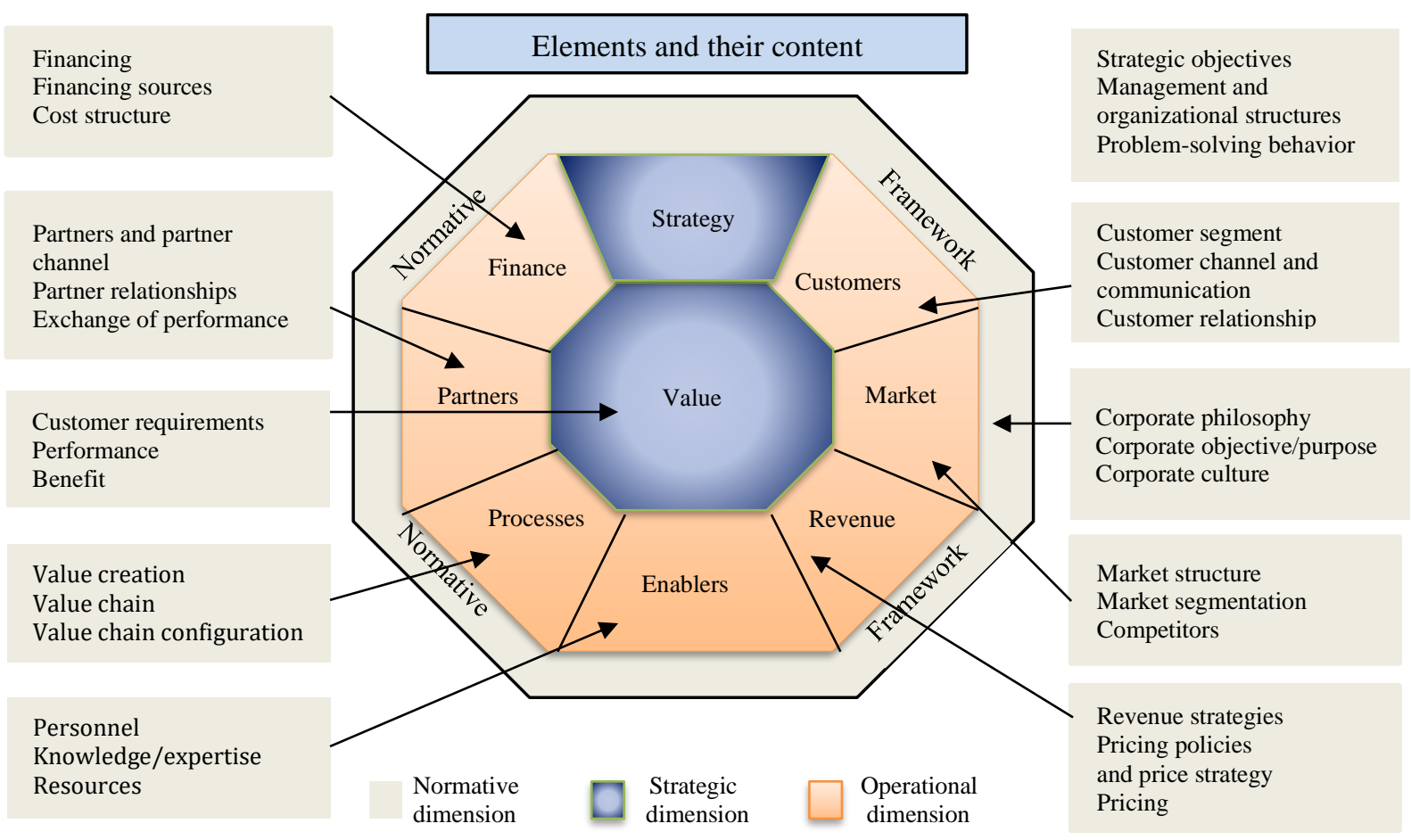

Figure 1. Components of the iOcTen model Source: Doleski (2015) 
The existence of three elements or concepts is observed: the normative dimension, the strategic dimension and the operational dimension. The normative dimension refers to the main concepts used by the model: customer, market, revenue, enablers (processes), processes, partners and finances. Strategic dimension refers to the strategic objectives, the organizational and management structures and the problem-solving behavior.

Operational concepts are associated with each normative concept. For example, the concept of Value includes Customer requirements, Performance and Benefit. The concept of Customer is operationalized, at the operational level, by the Customer Segment, the Channel towards the customers and the communication with them, respectively the Customer Relationship. Market concept is operationally associated with Market Structure, Market Segmentation and Competitors. The concept of Revenue is described by the following components: Revenue strategies, Pricing policy and price strategy and Pricing. The concept of Enablers includes: Personnel, Knowledge/expertise and Resources.

At the level of a company, each operational concept is materialized and described with the help of advanced operations, which represent the concrete modalities that are used in each case separately to meet the requirements of the concepts used. (Kaiser and Doleski, 2020).

\section{Methodology}

Business models that focus on permanently improving the efficiency of the value chain are no longer sufficient.

In order to identify the real and potential disturbances, a method is used that offers the possibility to identify and analyze in depth the disturbing factors. This method uses three major components. The first component starts from the concepts of first order and second order impact, which are related to the disruption interruption already started, which initially helps the existing business structure, but then continues to undermine it. The second important component is the disturbance assessment matrix (DAM) and the third component is the disturbance impact assessment (DIE), a detailed analysis tool which determines the intensity of the impact of the disturbance on the main stakeholders in the respective business (Steward B. et al., 2017).

Digital disruption takes place in successive stages whereby the initial benefits obtained by digitization are subsequently lost through continuous digitization. The concept of the impact order is well known from the business model developed by (Westerman et al., 2014).

"Figure 2" shows the disturbance evaluation matrix (DAM).

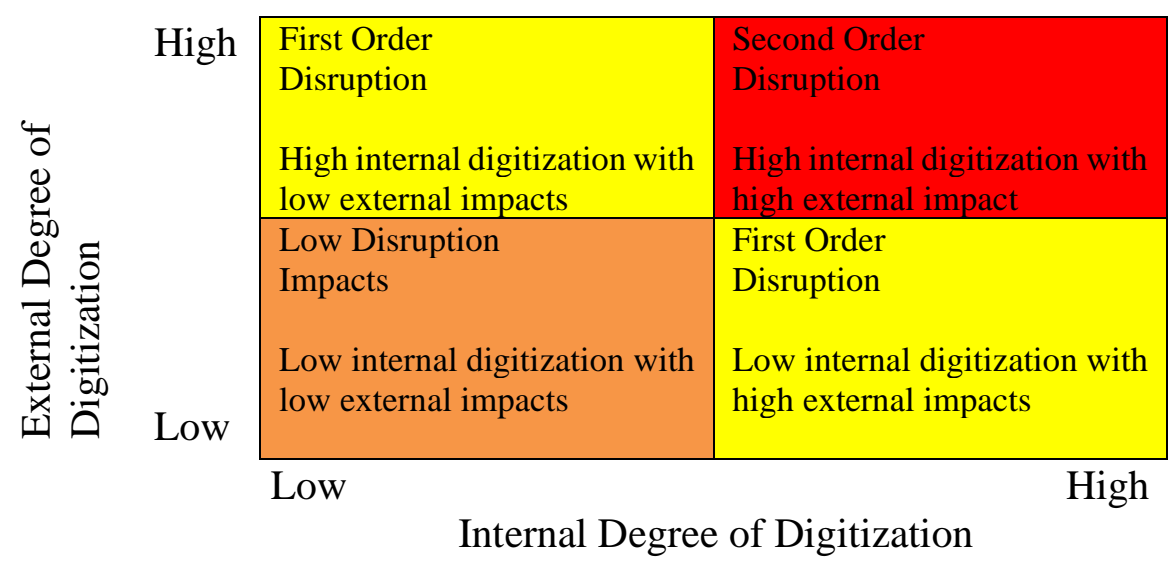

Figure 2. The disturbance evaluation matrix (DAM) Source: Stewart B. et al. (2017) 
"Figure 2" gives a graphical description of the method and evaluation of the characteristics of a potential change in the position of a firm or banks due to the digitization. The grid can be viewed as a combination of standard PESTLE analysis, environmental risk assessment, scenario planning and a set of competitive Porter analyzes (Porter, 2008).

Table 1. Disruption assessment matrix (DAS)

\begin{tabular}{|l|l|l|l|l|l|l|}
\hline \multicolumn{1}{|c|}{$\begin{array}{c}\text { Domains/ } \\
\text { Stakeholders }\end{array}$} & $\begin{array}{c}\text { Legal, } \\
\text { political }\end{array}$ & $\begin{array}{c}\text { Economic } \\
\text { and business }\end{array}$ & $\begin{array}{c}\text { Health and } \\
\text { Wellness }\end{array}$ & $\begin{array}{c}\text { Cultural, ethical } \\
\text { and moral }\end{array}$ & $\begin{array}{c}\text { Techno- } \\
\text { logical }\end{array}$ & Environmental \\
\hline Owners & & & & & & \\
\hline Investors intern/extern & & & & & & \\
\hline $\begin{array}{l}\text { Stock } \\
\text { markets }\end{array}$ & & & & & & \\
\hline Producers & & & & & & \\
\hline Employees & & & & & & \\
\hline Managers & & & & & & \\
\hline Consumers & & & & & & \\
\hline$\ldots$ & & & & & & \\
\hline
\end{tabular}

Source: Stewart B. et al. (2017)

In the disturbance assessment matrix (DAM), are represented six domains that determine people's actions and behaviors (Legal and regulatory, political; Economic and business; Health and wellness; Cultural/social/ethical and moral; Technological; Environmental).

The Digitalization Impact Evaluation (DIE) framework ("Table 2") provides a segmentation of the population to assess the impact of each domain on each stakeholder group.

Table 2. Digitalization impact evaluation (DIE)

\begin{tabular}{|l|l|l|l|l|l|}
\hline \multicolumn{1}{|c|}{ Impact } & No impact & $\begin{array}{c}\text { Impacts } \\
\text { profitability }\end{array}$ & $\begin{array}{c}\text { Impacts } \\
\text { growth }\end{array}$ & $\begin{array}{c}\text { Impacts } \\
\text { existing } \\
\text { scale }\end{array}$ & $\begin{array}{c}\text { Severe } \\
\text { disruption } \\
\text { Impacts survival }\end{array}$ \\
\hline $\begin{array}{l}\text { Owners and } \\
\text { Investors }\end{array}$ & & & & & \\
\hline Reduce the risk of capital loss & & & & & \\
\hline Improve portfolio performance & & & & & \\
\hline Producers & & & & & \\
\hline Increase profitability & & & & & \\
\hline $\begin{array}{l}\text { Enhance customer } \\
\text { relationships }\end{array}$ & & & & & \\
\hline Customers & & & & & \\
\hline Speed of delivery & & & & & \\
\hline Lower cost & & & & & \\
\hline Public & & & & & \\
\hline Improve Environmental Performance & & & & & \\
\hline Reduce carbon output & & & & \\
\hline
\end{tabular}

Source: Stewart B. et al. (2017)

The impact assessment of digitization (DIE) is used together with the DAM as an initial step to determine the degree of impact that a digital innovation will have on the various stakeholder groups.

\section{Results and discussions}

The disruption caused by the FinTech and BigTech in almost all areas of finance and banking creates a pressing need for new and radical solutions. This is also true for business models.

Some of the most important disruptions that have been manifested in the banking field and how they are reflected in changing the structure of the business models are presented below:

a) Introduction of specialized platforms 
www.conferenceie.ase.ro

As a rule, FinTech focus on the most profitable banking services, such as managing personal accounts or SMEs, which represent about $50 \%$ of the profits made by banks (Wewege, L. and Thomsett, M.C., 2020).

FinTech companies offer a variety of electronic payment solutions and FinTech's development has facilitated the circulation of virtual and crypto money, which was impossible using only traditional banking systems. All of these solutions are integrated into decentralized blockchain architectural structures, which have a large extension among the different categories of clients, ensuring a particularly high level of communications security.

b) Covering neglected customer segments

Traditional banks usually exclude a significant part of the population. Based on 2019 International Finance Corporation data, 45-55\% of SMEs worldwide do not have an overdraft allowance, but would benefit from one, while $21-24 \%$ although they have accessed loans, they are in very limited of different regulations. Worldwide, there are another $\$ 2.4$ trillion in credit applications.

By offering alternative lending services, fintech companies offer innovative approaches to segments such as subprime lending, which are not served by traditional banking services. Financing sindicate Kabbage, Lendio, OnDeck and Swift Capital are some of the players who have made use of the 20\% decrease in bank loans to SMEs after the 2007 and 2008 crisis. By adopting FinTech and BigTech technologies, traditional banks can apply digital lending models to assess the creditworthiness of customers whose financial profiles do not comply with traditional lending rules.

c) Improve customer selection

The concept of Big Data has shown its full value when it began to be used in business models of banks. By combining internal data sources with other external sources, commercial banks are improving their pricing strategies, which can sometimes have very complex structures. This richness and variety of information, along with their complexity can also be used to decide how to classify customers and which products are most recommended for each type of activity they carry out. Some of the new FinTech technologies in the US use over 2000 different data points from over 100 sources to make a credit decision.

d) Reduction of the operating costs of commercial banks

Fintech can create services, platforms and products with a small budget. The various innovations suggested by FinTech can be used to reduce the operating costs of the respective banking system. Standardizing and digitizing banking processes allows FinTech to sell products and services at substantially lower prices.

e) Optimization of the business process of the banks

The increasingly widespread use of FinTech technology enables the automation of banking transactions, and customers can make payments using mobile phones and tablets.

\section{Conclusion}

Developing suitable business models for the banks is today a top priority. Business models create the conceptual framework for the systematic realization of digital business ideas and open up new business areas, therefore, they represent the practically available toolkit for the implementation of advanced initiatives.

The FinTech makes it impossible to run a business based on conventional operations, the strictly traditional approaches used so far prove to be outdated. The advent of BigTech technologies would be both a blessing and a curse for banks and financial institutions, as it opens up new opportunities with one hand and threatens to kill existing business models with the other (Schallmo et al., 2017). 
www.conferenceie.ase.ro

Focus on well-individualized services enables FinTech and BigTech companies to provide efficient services with new technologies, including those based on artificial intelligence. Artificial intelligence algorithms play an increasing role in determining customer scoring, identifying bank frauds, or segmenting customers.

\section{References}

[1] A. Afuan and C. Tucci, "Internet Business Models and Strategies - Text and Cases," 2nd ed., Boston, McGrow Hill, 2003.

[2] A. Osterwalder, "The Business Model Technology a Proposition in a Design Science Approach," PhD Thesis, University of Lausanne, Swizerland, 2004.

[3] A. Osterwalder and Y. Pigneur, Y, "Business Model Generation," London School of Economics, April, 2010.

[4] B. Stewart, R. Schatz and A. Khare, "Making Sense of Digital Disruption Using a Conceptual Two-Order Model," In: Khare A., Stewart B., Schatz R. (eds) Phantom Ex Machina. Springer, Cham, 2017.

[5] C. Zott, R. Amit and L. Massa, "The Business Model: Recent Developments and Future Research,” Journal of Management, Vol.37, 2011.

[6] D. Amel and S.A. Rhodes, "Strategic Groups in Banking," The Review of Economics and Statistics, Vol. 70, pp. $685-689,1999$.

[7] D. Schallmo and C. A. Williams \& L. Boardman, "Digital Transformation of Business Models - Best Practice, Enablers, and Roadmap, International Journal of Innovation Management, Vol. 21, No. 8, 2017.

[8] EBA (2017). EBA Report on the Leverage Ratio Requirements under Article 511 of the CRR, EBA/Op/2016/13.

[9] FSB (2019). FinTech and market structure in financial services: Market developments and potential financial stability implications.

[10] Joe H. Ward, Jr, "Hierarchical grouping to optimize and objective function," Journal of the American Statistical Association, 58(301), pp. 236-244, 1963.

[11] J. Mütze and A. Gerloff, Customer Value Co-Creation: Gemeinsam die Chancen der Digitalisierung, Realisierung Utility 4.0 Band 1. Springer Vieweg, 2019.

[12] L. Wewege, and M.C. Thomsett, The Digital Banking Revolution. How FinTech Companies are Transforming the Retail Banking Industry through Disruptive Financial Innovation, De Gruyter, 3rd Ed., 2020.

[13] M.E. Porter, "The Five Competitive Forces that Shape Strategy," Harvard Business Review, Jan., 86 (1), pp. 79 -83, 2008.

[14] M. Viki and H. L.A. Kiers, "Factorial K-means analysis for two-way data," Computational Statistics \& Data Analysis, 37(1):49-64, 2001.

[15] O. D. Doleski, Integrated Business Model. Applying the St. Gallen Management Concept to Business Models, Springer Essentials. Wiesbaden: Springer Gabler, 2015.

[16] R. Ayadi, Arbak and W. Groen, "Business Models in European Banking: A Pre-and PostCrisis Screening," SSRN Electronic Journal, 2011.

[17] R. Casadesus-Masanell and J.E. Ricart, "From Strategy to Business Models and onto Tactics," Long Range Planning, vol. 43, pp. 195- 215, 2010.

[18] R. Casadesus-Masanell and F. Zhu, "Business Model Innovation and Competitive Imitation: The Case of Sponsor-Based Business Models," Strategic Management Journal 34, no. 4, pp. 464-482, 2013.

[19] T. Kaiser, O.D. Doleski, "Advanced Operations. Best Practices for the Focused Establishment of Transformational Business Models," Springer Vieweg, 2020, ISBN 9783-658-27585-3. 